\title{
LA AUTONOMÍA DE LA VOLUNTAD EN EL PROCESO PENAL: PERSPECTIVAS DE FUTURO*
}

\author{
Julio MUERZA ESPARZA \\ Catedrático de Derecho Procesal \\ UNIVERSIDAD DE NAVARRA
}

SUMARIO: I. Introducción. II. La autonomía de la voluntad. III. Autonomía de la voluntad y proceso penal. IV. Autonomía de la voluntad del acusado. V. La mediación penal. VI. Conclusiones.

RESUMEN: El presente trabajo se centra en el juego de la autonomía de la voluntad en el proceso penal, a través del examen de los principios esenciales de este proceso y del acercamiento a la configuración y a las posibilidades de la mediación como instrumento para la resolución de un hecho que reviste caracteres de delito.

PAlabras ClAVE: autonomía de la voluntad, principios del proceso penal, mediación penal.

\section{FREE WILL IN CRIMINAL PROCEEDINGS: FUTURE PROSPECTS}

ABSTRACT: This work focuses on the consideration of free will in criminal proceedings, through the exam of its essential principles, and configuration, and in mediation possibilities as conflict resolution instrument.

KEYWORDS: Free will, criminal proceedings principles, criminal mediation.

\section{Introducción}

Tradicionalmente cualquier estudio del proceso penal se inicia afirmando que este puede definirse como una variedad del proceso, junto al proceso civil, contenciosoadministrativo o laboral. El elemento común a todos ellos es que constituyen el instrumento a través del cual se desarrolla la función jurisdiccional del Estado. Ahora bien, el calificativo «penal» permite afirmar que en esta variedad de proceso la función jurisdiccional se concreta en la protección del ordenamiento jurídico penal, del derecho penal sustantivo.

\footnotetext{
* Texto basado en el ponencia que, con el mismo título, fue presentada al Congreso sobre Mediación $y$ Arbitraje Nacional e Internacional: Perspectivas de futuro, celebrado en Logroño los días I4 y I5 de marzo de 20II. El estudio se ha realizado al amparo del Proyecto Nacional I+D «Instrumentos de Justicia Restaurativa en el proceso penal español: hacia una regulación de la mediación penal» (Ref. DER 2008-03547/JURI).
} 
Esta rama del ordenamiento jurídico, el derecho penal, tiene como fin, es decir, como razón de su existencia, el mantenimiento de la paz social, proteger a la sociedad de las conductas más intolerables (última ratio); y sus funciones (para qué es útil) pueden ser diversas: retributiva, prevención, etc.

Por otra parte, el Derecho penal sustantivo puede ser definido desde dos perspectivas: objetiva, como conjunto de normas que regulan los delitos las penas y las consecuencias del delito; y, subjetiva, como el derecho del Estado a establecer, imponer y ejecutar penas (ius puniendi).

Desde esta última perspectiva, se puede concluir entonces que el proceso penal es el instrumento a través del cual se desarrolla el ius puniendi del Estado. Es, además, el único instrumento para ello. Como afirmaba CARNELUTTI, los términos delito, pena y proceso son rigurosamente complementarios. En efecto, la fórmula del principio de legalidad penal («nullum crimen nulla poena sine previae lege») debe completarse con la de ( $«$ sine previae indicio»), es decir, resulta imprescindible la existencia de un proceso previo para que pueda imponerse la pena a un sujeto por la comisión de un hecho tipificado como delito.

Partiendo de este concepto de proceso penal, los principios que lo sustentan son básicamente los siguientes:

A) Principio de necesidad: el proceso es el instrumento fundamental para hacer realidad el ius puniendi del Estado (art. I LECrim). Esta obligatoriedad del proceso la reconoce el Estado de forma que ese ius puniendi no lo hace valer directamente sino a través de los órganos jurisdiccionales y siguiendo la vía del proceso a la que el mismo se somete (no ocurre así en el derecho civil, en el que el proceso no es necesario para la resolución de un conflicto).

B) Principio de legalidad: es garantía y complemento del anterior y se encuentra previsto también en el artículo I LECrim cuando afirma: «No se impondrá pena alguna,... sino de conformidad con las disposiciones del presente Código o de Leyes especiales...». Este principio significa que el proceso penal debe ser incoado tan pronto se tenga conocimiento de la existencia de un hecho con apariencia de delito, siguiendo lo previsto por el ordenamiento jurídico.

C) Principio de Inmutabilidad: el objeto fundamental proceso penal no puede cambiar, es el ius puniendi del Estado. Ello significa que, con carácter general, por encima del interés que tenga el ciudadano está el interés del Estado en que se cumpla la ley penal.

Junto a estos tres principios, que derivan del propio fin que persigue $-o$ que tradicionalmente ha perseguido- el proceso penal, debemos referirnos a los principios técnicos que lo informan: el de oficialidad y el de investigación de oficio, que se corresponden con el principio dispositivo y de aportación de parte del proceso civil.

D) Principio de oficialidad: es aquel criterio derivado del interés público predominante previsto en la ley por el cual el proceso, su objeto, los actos que lo conforman y la sentencia no están subordinados al poder de disposición de los sujetos jurídicos en relación con la tutela de sus derechos sino que dependen de que aquel interés público se ponga de manifiesto al órgano jurisdiccional y se haga valer por órganos públicos ante situaciones subsumibles en la ley (DE LA OLIVA). Principio del que se exceptúan los denominados delitos privados (art. IO4 LECrim)

E) Principio de investigación de oficio: en relación con la aportación y comprobación de los hechos, este principio, en contraposición con el principio de aportación de parte del proceso civil, significa que el órgano jurisdiccional en la fase de instrucción, no puede dejar de introducir en el proceso hechos y circunstancias, tanto 
incriminatorias como exculpatorias -art. 2 LECrim- y en la fase de juicio oral, «las diligencias de prueba no propuestas por las partes», en virtud de lo dispuesto en el artículo 729.2 LECrim (precepto sobre el que existe jurisprudencia contradictoria, en relación con el principio acusatorio).

F) En la actualidad, al exponer una relación de los principios que informan el proceso penal no puede dejar de hacerse referencia al principio acusatorio y sistema acusatorio. A los efectos que aquí interesa baste indicar que se trata de dos expresiones muy usadas por la doctrina y jurisprudencia hasta tal punto que no se sabe muy bien cuál es su significado. Bajo la expresión «principio acusatorio» se comprenden muchas cosas, relacionadas entre sí, pero sin que esa relación sea esencial y, por tanto, necesaria. Así, se afirma que el principio acusatorio implica: a) que el proceso, desde el principio o sólo en la parte decisiva, ha de desarrollarse como una contradicción igualitaria con una imprescindible parte acusadora; b) que sean diferentes los órganos instructor y enjuiciador; c) que exista correlación entre la acusación y sentencia, estando el tribunal vinculado a ésta; d) que la acusación no es sólo la imputación de hechos a una persona o personas concretas y determinadas sino también la calificación jurídica de los hechos; e) la prohibición de la reformatio in peius.

En esta relación de criterios, como se puede observar, existen todo un conjunto de reglas, unas necesarias, pero otras contingentes y además discutibles (qué ha de entenderse por acusación; desde cuándo o para qué se necesita una acusación; hasta dónde debe llegar la correlación entre acusación y sentencia) que independientemente de la respuesta que se dé no impedirían calificar el proceso de acusatorio.

En esencia, el principio acusatorio puede definirse como el criterio configurador del proceso penal según el cual se necesita una acusación -la imputación a una o varias personas concretas de unos determinados hechos- para el inicio de la fase de juicio oral y para una sentencia de condena (DE LA OLIVA). Esta necesidad se traduce en dos consecuencias: $\mathrm{I}^{\mathrm{a}}$ ) no puede haber juicio sin que se formule acusación; $2^{\mathrm{a}}$ ) el juez no puede dictar sentencia sobre personas distintas de las acusadas ni sobre la base de hechos distintos de los objeto de acusación. Entendido así parece que el principio acusatorio no tiene que ver con las exigencias del derecho de contradicción o de defensa..

Por su parte, bajo la expresión «sistema acusatorio» se incluye lo que tradicionalmente ha sido denominada forma contradictoria y sus consecuencias, aplicada al proceso penal.

\section{La autonomía de la voluntad}

De lo hasta aquí expuesto, que no es más que un recordatorio de los conceptos básicos sobre el proceso y el derecho penal, resulta, en principio, «sorprendente», relacionar a aquél con la autonomía de la voluntad al estilo de cómo se habla de ella en el proceso civil.

En sentido muy general se entiende por autonomía privada «el poder de autodeterminación de la persona» (FEDERICO DE CASTRO). Más concreto, «aquel poder complejo reconocido a la persona para el ejercicio de facultades, sea dentro del ámbito de libertad que le pertenece como sujeto de derechos, sea para crear reglas de conducta para sí y en relación con los demás, con la consiguiente responsabilidad en cuanto actuación en la vida social» (FEDERICO DE CASTRO).

Por su parte la «autonomía de la voluntad», como manifestación de la autonomía privada, consiste en «el poder atribuido a la voluntad respecto a la creación, modificación o 
extinción de relaciones jurídicas». También tiene aquélla como manifestación «el poder de esa voluntad referido al uso, goce y disposición de poderes, facultades y derechos subjetivos» (FEDERICO DE CASTRO).

Trasladando estos conceptos al ámbito del proceso civil nos encontramos con que éste tiene como base, precisamente, la naturaleza privado disponible de las situaciones jurídicas sustanciales cuya satisfacción se pretende, mientras que cuando se trata del proceso penal, la base se encuentra como ya hemos dicho, no situaciones jurídico sustanciales de naturaleza privada, sino en el ius puniendi.

Por tanto, como sostenía al comienzo no parece, en principio, que esos conceptos clásicos entorno a la autonomía de la voluntad puedan ser aplicados a la concepción que hemos expuesto de nuestro proceso penal regulado en la Ley de Enjuiciamiento Criminal de I882, lo que no impide que tratemos de ello, de forma más desarrollada seguidamente.

\section{Autonomía de la voluntad y proceso penal}

A) Como indicaba en el epígrafe introductorio el principio de legalidad informa el proceso penal. O lo que es lo mismo, la ley es la única guía para tribunales y acusador público (art. I24.2 CE) y, por tanto, también para el proceso: el Ministerio fiscal acusará o no, según la ley y el tribunal dictará sentencia según la ley.

Sin embargo desde hace tiempo convive con ese principio el denominado principio de oportunidad que consiste, esencialmente, en que en vez de los referidos parámetros legales, sean criterios de oportunidad los determinantes de toda una serie de importantes piezas y elementos del Derecho y de la Justicia penales: desde la iniciación o no del proceso hasta la imposición o no de la pena.

Conviene precisar, además, que tal principio de oportunidad se configura como un régimen de alternativa o excepción al principio de legalidad que afecta sobre todo al comportamiento del Ministerio Fiscal. Así entendido, se puede definir como aquél principio en virtud del cual el deber del Estado de imponer penas no habría de ser cumplido, siempre según los criterios legales en todos los casos en que concurriesen sus presupuestos (conducta tipificada) sino que estaría condicionado al poder atribuido al Ministerio Fiscal $u$ órgano similar para disponer, con amplio arbitrio o bajo las condiciones previstas específicamente en la Ley (oportunidad reglada) del ejercicio y del modo de ejercicio de la acción penal, independientemente de que se hubiese conocido la existencia de un hecho de apariencia punible y de que apareciesen unos presuntos autores del mismo. (Nótese que, en la «oportunidad reglada», no es la oportunidad la que se somete a reglas -el juicio de oportunidad consiste en decidir lo que resulta oportuno- sino el ámbito objetivo en el que caben los juicios de oportunidad).

B) En España, a pesar de que con base en el artículo I24.2 de la Constitución resulta muy difícil su admisión, el principio de oportunidad se introdujo con la regulación del proceso abreviado para determinados delitos en I988 a través de la denominada «conformidad» y la interpretación que sobre la misma estableció la Fiscalía General del Estado en su Circular I/ı989, de 8 de marzo, con el principio del consenso. En concreto, los artículos 779.I. $5^{\mathrm{a}}$, 784.3 y 787 de la LECrim prevén los diferentes momentos del procedimiento en que puede producirse. Figura que amplió su aplicación al proceso ante el Tribunal del Jurado (art. 50) y en el denominado proceso para el enjuiciamiento rápido de determinados delitos (art. 80 IECrim). 
Ante esta situación ¿Tienen sentido los avances del derecho penal si el principio de legalidad y también el de igualdad (tratar igualmente a iguales y desigualmente a desiguales) son sustituidos por apreciaciones de oportunidad?.

Si miramos hacia atrás, desde la última reforma derivada de la LO 5/20I0, 22 de junio, hasta el Código Penal de I995, se han producido 27 reformas en el derecho penal sustantivo (es verdad, en parte, por exigencias de la Unión Europea). En la última, a título de ejemplo, en materia de atenuantes -dilaciones indebidas-; responsabilidad penal de personas jurídicas; revisión de penas (localización permanente, trabajos en beneficio de la comunidad, expulsión de extranjero); se han incorporado nuevos delitos (tráfico de órganos; más intervención penal en el ámbito informático, ordenadores, programas y red; modificación en delitos sobre tutela de la propiedad intelectual; delitos urbanísticos, medio ambiente,.....). Y, todo esto, nos podemos preguntar ¿para qué?.

C) En el Informe que presentó el Consejo General del Poder Judicial de I992 al Anteproyecto de Código Penal se afirmaba, entre otras cosas: «El principio de legalidad, concebido retributivamente coloca al Estado en la necesidad de reaccionar ante los delitos con la pena adecuada y la culpabilidad del autor, por más que pueda resultar inútil o contraproducente». Y seguía: «pero la formulación constitucional del mismo (art. 25.I CE) no expresa tal cosa. No configura el principio de legalidad como un deber de castigar, sino como un límite del ius puniendi del Estado. De ahí la formulación negativa (Nadie puede ser condenado o sancionado por acciones $u$ omisiones que en el momento de producirse no constituyan delito, falta o infracción administrativa, según la legislación vigente en aquel momento) a lo que no acompaña la positiva (Todos los que cometan un delito, falta o infracción administrativa han de ser sancionados con la pena correspondiente)».

A continuación, afirmaba: «Con razón ha hablado la jurisprudencia constitucional de la legalidad como un derecho susceptible de amparo: aquel principio negativo que, desde la perspectiva del imputado o condenado, es un derecho fundamental, no se quebrante porque, allí donde la pena adecuada a la culpabilidad no cumple sus fines, pueda ser sustituida por otras más leves, o por medidas o, simplemente, pueda renunciarse a ella». «Y esta conclusión se proyecta sobre el proceso: el principio de necesidad de ejercicio de la acción penal por el Ministerio Fiscal, debiera paliarse de forma que, sin merma del principio de legalidad proclamado en la Constitución, pudiera evitarse el juicio en las infracciones menores, cuando ha desaparecido el interés social en el castigo, o el presunto culpable ha sufrido ya un poena naturalis u otro tipo de circunstancias o compensaciones que hacen innecesario el recurso al Derecho criminal.... Sólo la pervivencia de una discutible «mentalidad retributiva» dificulta que nuestro ordenamiento pueda acudir a esa o parecidas fórmulas, de las que tan necesitada se halla la justicia penal para poder llegar a ser, realmente, efectiva. Y sólo la pervivencia de esa mentalidad pone en tela de juicio la ampliación de mecanismos que eviten el pronunciamiento o la ejecución de la condena, allí donde los fines de la pena no sufran quebranto o provoque actitudes renuentes ante la emergencia de posibilidades de sustituir la pena privativa de libertad».

D) Frente a lo afirmado en este Informe, cabe decir que el artículo 25.I CE si bien no formula expresamente el ius puniendi como deber del Estado de castigar sí lo presupone. Además, conviene precisar que el principio de legalidad no sólo es un límite del ius puniendi, sino que pertenece también al fundamento de ese peculiar derecho. Por último, el principio de necesidad de ejercicio de la acción penal forma parte del artículo I24.2 CE por lo que es imposible paliar parte del contenido esencial del principio de legalidad sin merma de ese mismo principio. En definitiva, no parece que quepa en nuestro marco constitucional atribuir al Ministerio Fiscal, en virtud de un juicio de oportunidad, la facultad de dejar de acusar o dejar de calificar una conducta tipificada como delito. 
Cuestión distinta es que se prevean legalmente alternativas a la pena, se dejen de castigar penalmente ciertas conductas,... lo que indudablemente tiene naturaleza sustantiva, no procesal, independientemente del lugar sistemático donde tal cuestión se ubique.

Pero, si el Código Penal tipifica un hecho como delito al que le impone la correspondiente pena y tal hecho se produce en la realidad, el principio de legalidad exige que tal hecho se investigue, se determine quien es su autor, y, tras la celebración del juicio correspondiente, si de la práctica de la prueba se deduce su culpabilidad, en la sentencia se le imponga la pena prevista en aquél.

\section{Autonomía de la voluntad del acusado}

Como ya hemos indicado anteriormente al proceso penal no resulta trasladable el concepto de autonomía de la voluntad tradicional de la teoría general del derecho, lo que no quiere decir, que el imputado no pueda «decidir» sobre cuestiones concretas que se puedan plantear en el proceso. Así:

a) El artículo 24-2 de la Constitución establece las denominadas garantías constitucionales del proceso, algunas de las cuáles constituyen un ejemplo de la autonomía que tiene el acusado, como son, el derecho a no declarar o el derecho a guardar silencio, con trascendencia en la fase probatoria.

b) En relación con el derecho de defensa, que en el proceso penal encuentra diferentes manifestaciones (defensa material, defensa formal y autodefensa), el acusado tiene la posibilidad de por sí mismo, ejercer este derecho (autodefensa), por ejemplo, en el denominado «derecho a la última palabra» previsto con carácter general en el artículo 739 de la norma procesal penal.

c) Excepcionalmente, la autonomía de la voluntad del acusado sí puede estar presente en el proceso penal, con el mismo significado que tiene en el proceso civil. Ello se producirá cuando se ejercite la acción civil en aquél proceso. En efecto, la posibilidad de que la restitución, reparación o indemnización de daños y perjuicios derivados de la comisión de unos hechos que revisten caracteres de delito, puedan ser reclamados dentro del proceso penal, ejercitando la acción civil correspondiente, constituye, sin duda, una manifestación de aquélla autonomía de la voluntad. A estos efectos, la norma procesal establece que ejercitada la acción penal se entenderá ejercitada la acción civil, a no ser que el dañado o perjudicado renuncie a su ejercicio o la reserve expresamente para ejercitarla después de finalizar el proceso penal (arts. II2 y ss.). Como se puede observar, el ejercicio de esta acción civil está informada, lógicamente, por los mismo principios técnicos del proceso civil (principio dispositivo y principio de aportación de parte).

\section{La mediación penal}

Si a finales de la década de los años 80 comenzó a introducirse en España el denominado principio de oportunidad en el proceso penal, podemos decir que desde finales del siglo pasado existen fuertes tendencias a incorporar al proceso penal técnicas de resolución de conflictos, hasta entonces previstas en el ámbito del proceso civil, como es la mediación. Es más, desde la propia Unión Europea se alienta a incorporar esta institución al proceso penal.

En concreto, el artículo I.I de la Decisión Marco del Consejo de la Unión Europea de I5 de marzo de 200I (200I/200/JAI) relativa al estatuto de la víctima en el proceso penal, define la mediación en causas penales como «la búsqueda antes o durante el proceso 
penal de una solución negociada entre la víctima y el autor de la infracción en la que media una persona competente». Y el artículo io establece el compromiso de los Estados para impulsar la mediación penal para aquellas infracciones que a su juicio se presten a este tipo de medidas.

Al hablar de la mediación penal suele afirmarse que constituye un sistema de gestión de conflictos en el que una parte neutral, con carácter técnico y en posesión de conocimientos y habilidades específicas, independiente de los actores institucionales del proceso penal e imparcial, ayuda a dos o más personas implicadas en un delito o falta, en calidad de víctima e infractor -o en ambas posiciones en los supuestos de denuncias cruzadas-, a comprender el origen del conflicto, sus causas y consecuencias, a confrontar sus puntos de vista y a elaborar acuerdos sobre el modo de reparación, tanto material como simbólica.

Como se puede observar, en este concepto aparecen expresiones que se alejan absolutamente de las que resultan propias en relación con un proceso penal. Así: I ${ }^{\circ}$ ) El delito no resulta ser ya una conducta típicamente antijurídica, sino un «conflicto». $2^{\circ}$ ) La reparación del daño y la disminución de los efectos delito adquieren una relevancia extraordinaria en detrimento de la pena. 3) Comprender cuál ha sido el origen, causa y consecuencias de ese «conflicto» y resolverlo mediante un acuerdo resulta ser mucho más importante que la persecución del delito.

Basta lo expuesto para darse cuenta que la mediación choca frontalmente con el concepto y fines tradicionales, ya expuestos, del proceso penal. Por supuesto que, como afirma la Decisión Marco de la Unión Europea, se puede instaurar este sistema de gestión de conflictos. Ahora bien, a mi entender, tal instauración supondrá, para aquellas conductas -delitos- susceptibles de seguir este sistema de resolución, que habrán novado su naturaleza. En efecto, no les resultarán aplicables las características típicas de las mismas debido, digámoslo ya, a su «privatización» a través de esta institución. $\mathrm{O}$, si se prefiere, si existe la posibilidad de someter a la mediación ciertas conductas tipificadas como delito, estas deberán encuadrarse en una nueva categoría de delitos privados.

Admitida la institución, obviamente será necesario establecer un procedimiento y hará falta prever a un sujeto que lo controle. ¿Deberá ser un Juzgado o Tribunal? La respuesta afirmativa deviene razonable pues no debemos olvidar que cuando de conductas delictivas se trata están en juego los derechos fundamentales y parece lógico que sean los órganos jurisdiccionales los que lleven a caso ese control.

Por otra parte, de la definición propuesta resulta que la mediación aparece configurada como un instrumento para «elaborar acuerdos» entre agresor y víctima, lo que permite afirmar que estamos ante una manifestación del principio de oportunidad.

En España la LO 5/2000, de I2 de enero, sobre responsabilidad penal de menores, da cobertura legal a la mediación (art. I9). En relación con dicho precepto los tribunales, partiendo de la especialidad del proceso de menores y de que los principios que lo informan no son los mismos que en el proceso ordinario, sostienen que: «Especial relevancia adquiere... el principio de oportunidad, que confiere al titular público de la acción penal la potestad para disponer de la misma, a pesar de poder estar acreditada la comisión de un hecho punible por una persona, debiendo destacarse que en estos casos no se amplían las facultades del órgano judicial, sino que se limitan, fortaleciéndose las facultades del Ministerio Fiscal». Y añade: «Manifestaciones de dicho principio de oportunidad son la posibilidad de que el Ministerio Fiscal acuerde no incoar el procedimiento penal de menores al amparo de lo previsto en el artículo i8 LORPM, o los supuestos de desistimiento por corrección en el ámbito educativo y familiar o por resarcimiento anticipado o conciliación con el infractor a los que se refiere el artículo ig LORPM, o incluso... la posibilidad que se le concede de concluir el expediente solicitando su archivo, cuando el 
Equipo Técnico estime conveniente no continuar el expediente en interés del menor» (AAP Segovia de I2 de septiembre de 2008 -JUR 2009, 4I962-).

La lectura de este pronunciamiento judicial pone de manifiesto, por una parte, que en nuestro ordenamiento procesal penal la figura de la mediación supone una excepción al estar prevista en un procedimiento especial. Por otra, que se reconduce al principio de oportunidad hasta el extremo de que el Ministerio Fiscal puede acordar no incoar el expediente, a pesar de estar acreditada la comisión de un hecho delictivo.

Fuera de ese texto legal no existen más manifestaciones de este instituto en nuestro proceso penal. Sin embargo, poco antes de anunciarse la fecha de las próximas elecciones generales -20 de noviembre de 20II- el Ministerio de Justicia terminó de elaborar un Anteproyecto de Ley de Enjuiciamiento Criminal que contiene algunos preceptos dedicados a la mediación. No se trata de una nueva reforma de nuestro proceso penal, a añadir a las ya existentes. Constituye un texto completo de nueva planta que consta de nueve libros, precedidos de un título preliminar, y setecientos ochenta y nueve artículos, además de sendas disposiciones adicional y derogatoria, seis disposiciones transitorias y cuatro finales. Ciertamente, teniendo en cuenta cuáles son los plazos parlamentarios y el fin tan cercano de la presente legislatura, no parece que tal Anteproyecto pueda transformarse en Ley. No obstante, resulta oportuno comentar cuáles son las cuestiones más sobresalientes que presenta dicho texto en relación con el tema que nos ocupa, la mediación.

La lectura de la exposición de motivos de la norma (parágrafo XXVI) pone de manifiesto la relación existente entre la institución objeto de comentario y el principio de oportunidad. En efecto, «en el mismo marco del principio de oportunidad ha de ser comprendida la institución de la mediación. Ésta no puede consistir en una especie de renuncia del Estado a la titularidad exclusiva del ius puniendi. No se trata de otorgar a los particulares un poder omnímodo de disposición como el que les está atribuido en los estrictos supuestos de delito privado. Al contrario, la mediación ha de concebirse como un instrumento al servicio de la decisión expresa del Estado de renunciar a la imposición de la pena cuando ésta no es necesaria a los fines públicos de prevención y pueden resultar adecuadamente satisfechos los intereses particulares de la víctima». A continuación, afirma: «Aparece, así, la mediación como un mecanismo al servicio del principio de oportunidad. Será el fiscal el que -al apreciar la concurrencia de un supuesto que, por sus características específicas, permite acudir a un archivo por oportunidad o a la imposición de una pena reducida- pueda condicionar estas posibles opciones a la adecuada satisfacción de las víctimas. Podrá, de esta forma, como director de la investigación, impulsar, a través de la mediación y con el consentimiento de los afectados, la obtención de una solución reparadora de los intereses particulares en juego en función de la disminución o ausencia de interés del Estado en el castigo». Y añade: «En algunos casos, el resultado de la mediación podrá ser la falta de composición y la continuación del procedimiento penal en curso con todas sus consecuencias. En otros, esta institución podrá conducir a la finalización de las actuaciones con un archivo condicionado al cumplimiento de lo pactado o con una sentencia condenatoria en el marco de una conformidad premiada».

Pasando ya al articulado de la norma, la mediación penal aparece regulada en el libro I (disposiciones generales), título $\mathrm{V}$ (las formas especiales de terminación del procedimiento penal), capítulo III, comprendiendo los artículos I57 a I6I.

El artículo I57 previene cuáles son los principios a los que se sujeta la mediación: voluntariedad, gratuidad, oficialidad y confidencialidad. Además, establece el derecho que tienen las partes a ser informadas de sus derechos, de la naturaleza del procedimiento y de las consecuencias posibles de la decisión de someterse al mismo. Por último, el Ministerio Fiscal no tendrá conocimiento del desarrollo de la mediación hasta que ésta haya finalizado, en su caso, mediante la remisión del acta de reparación. 
El artículo 158 regula el procedimiento de la mediación. De su tenor literal se deduce: a) que es el Ministerio Fiscal, atendiendo a las circunstancias del hecho, «del infractor» y de la víctima el que podrá, de oficio o a instancia de parte, someter el proceso a mediación; b) que el inicio de este proceso no eximirá que se practiquen las diligencias indispensables para la comprobación del hecho delictivo; c) que dicho inicio se realizará mediante decreto y contendrá el plazo máximo de duración del procedimiento, que no podrá exceder de tres meses, remitiéndose el mismo a los equipos de mediación; d) que si las partes no consienten en someterse a la mediación se pondrá en conocimiento del Ministerio Fiscal, que continuará la tramitación del procedimiento; e) el equipo de mediación asignado podrá solicitar del Ministerio Fiscal la información que necesite sobre el contenido del procedimiento de investigación durante el desarrollo de las sesiones; f) por último, también podrá el juez, de conformidad con lo establecido en este artículo, previa audiencia del fiscal, acordar el sometimiento del procedimiento a mediación durante la ejecución.

Una vez concluido el procedimiento de la mediación, el artículo I59 regula las «consecuencias» o, si se prefiere, el resultado alcanzado en aquél, en los siguientes términos:

a) El equipo de mediación deberá emitir un informe con el resultado positivo o negativo de la actividad mediadora. Y, en el caso de ser positivo, irá acompañado del acta de reparación con los acuerdos alcanzados por las partes. Este documento deberá ir firmado por las partes y sus representantes legales, si los hubiere, entregándose una copia a cada una de ellas.

b) En el caso de que el informe incorpore el acta de reparación, el Ministerio Fiscal, valorando los acuerdos a los que hayan llegado las partes, las circunstancias concurrentes y el estado del procedimiento, podrá: $\mathrm{I}^{\circ}$ ) decretar el archivo por oportunidad de conformidad con lo establecido en la Ley -artículos I49 y I50-, imponiendo como reglas de conducta los acuerdos alcanzados por las partes. En estos casos, no serán de aplicación los requisitos establecidos en las letras a) y b) del artículo I49.I de esta ley; $2^{\circ}$ ) proceder por las reglas especiales del procedimiento de conformidad. En estos supuestos, las víctimas serán siempre oídas aún cuando no se hubieran personado y la sentencia de conformidad incluirá los términos del acta de reparación.

La regulación de la mediación se completa con los artículos i6o y i6 q que tratan, respectivamente, de la posibilidad de someter también el proceso a mediación cuando se esté en la fase de juicio oral y de que el sometimiento a la mediación durante la tramitación de los juicios de faltas interrumpirá el plazo de prescripción de la correspondiente infracción penal.

\section{Conclusiones}

Que la justicia penal necesita una profunda reforma es una afirmación sabida y repetida de forma constante por todos los que se acercan a esta parcela de nuestro ordenamiento jurídico. Pero, en este caso, no se trata con tal afirmación de insistir en la necesidad de que se elabore y promulgue una nueva Ley de Enjuiciamiento Criminal que se adapte a la realidad social de nuestro tiempo.

Cuando digo «profunda» reforma, me estoy refiriendo también a la necesidad de reflexionar sobre cuál debe ser el papel que debe jugar en nuestra sociedad el Derecho penal. Dicho de otra manera, el Parlamento, como órgano soberano que representa la voluntad de los ciudadanos, debe establecer qué conductas considera merecedoras de un reproche tal que su comisión merezca necesariamente la imposición de una pena. Pero, eso 
sí, por seguridad jurídica parece razonable exigir que, supuesta la comisión de ese hecho delictivo, a través necesariamente del proceso, se le imponga al sujeto acusado de aquél la pena correspondiente.

Del mismo modo y por las mismas razones, parece conveniente que, legalmente, se establezcan, en su caso, qué conductas, no obstante estar tipificadas como delito, pueden ser susceptibles de «negociación» por las partes de un proceso penal, a través de las figuras que el propio legislador prevea. Una de las cuáles puede ser la mediación.

Ahora bien, en el momento presente, cuando no se encuentra establecida legalmente, aparte el proceso de menores, la mediación como instrumento para resolver la comisión de un hecho que reviste caracteres de delito, me parece que acudir a ella y entroncarla en la Ley procesal penal en relación con la figura de la conformidad no es jurídicamente aceptable.

En el ordenamiento vigente cuando se comete un hecho tipificado en el Código Penal no estamos ante un «conflicto» entre autor y víctima sino ante un delito cuyo autor debe ser castigado con la pena prevista. Por lo mismo, la finalidad última que se persigue con el proceso no es «restaurar» a la víctima de los daños que le ha ocasionado la comisión de aquél delito, sino fundamentalmente hacer realidad el ius puniendi del Estado.

Únicamente si se privatiza el derecho penal, o si se prefiere, estableciendo legalmente qué conductas, no obstante ser constitutivas de un delito, el Estado no las persigue por entender que por encima del ius puniendi existen otros fines prioritarios como, por ejemplo, resarcir de los daños a la víctima que aquél le ha ocasionado -lo que podría entenderse como un tipo de delitos privados-, sería posible, a mi entender, aceptar figuras tales como la mediación.

Por todo lo dicho entiendo que la regulación que nos ofrece el Anteproyecto de Ley de Enjuiciamiento Criminal de 20II podría dar lugar a una inseguridad jurídica importante, puesto que deja al arbitrio del Ministerio Fiscal -que en dicho Anteproyecto resulta ser el sujeto que está al frente de la investigación penal, además de ser el acusador por excelencia- la decisión sobre qué causas pueden resolverse a través de la mediación. 


\title{
ANEXo
}

\section{ANTEPROYECTO LEY DE ENJUICIAMIENTO CRIMINAL DE 2OII}

\author{
LIBRO I \\ DISPOSICIONES GENERALES \\ TÍTULO V \\ LAS FORMAS ESPECIALES DE TERMINACIÓN DEL PROCEDIMIENTO PENAL \\ CAPÍTULO III \\ LA MEDIACIÓN PENAL
}

\section{Artículo 157. Principios}

I. La mediación se sujetará a los principios de voluntariedad, gratuidad, oficialidad y confidencialidad.

2. Las partes que se sometan a mediación, antes de prestar su consentimiento, serán informadas de sus derechos, de la naturaleza del procedimiento y de las consecuencias posibles de la decisión de someterse al mismo.

3. Ninguna parte podrá ser obligada a someterse a mediación, pudiendo, en cualquier momento, apartarse de la misma.

La negativa de las partes a someterse a mediación, o el abandono de la mediación ya iniciada, no implicará consecuencia alguna en el proceso penal. de mediación.

4. Se garantizará la confidencialidad de la información que se obtenga del proceso

El fiscal no tendrá conocimiento del desarrollo de la mediación hasta que ésta haya finalizado, en su caso, mediante la remisión del acta de reparación.

\section{Artículo 158. Procedimiento}

I. El Ministerio Fiscal, según las circunstancias del hecho, del infractor y de la víctima, podrá, de oficio o a instancia de parte, someter el proceso a mediación.

El inicio del proceso de mediación no eximirá de la práctica de las diligencias indispensables para la comprobación de delito.

2. El decreto que lo acuerde se remitirá a los equipos de mediación, fijando un plazo máximo para su desarrollo, que no podrá exceder de tres meses.

3. De no consentir las partes en someterse a mediación, se pondrá inmediatamente esta circunstancia en conocimiento del Ministerio Fiscal que continuará la tramitación del procedimiento.

4. El equipo de mediación podrá solicitar al fiscal la información que precise sobre el contenido del procedimiento de investigación durante el desarrollo de las sesiones.

5. También podrá el juez, de conformidad con lo establecido en este artículo, previa audiencia del fiscal, acordar el sometimiento del procedimiento a mediación durante la ejecución. 


\section{Artículo 159. Consecuencias}

I. Concluido el proceso el equipo de mediación emitirá un informe sobre el resultado positivo o negativo de la actividad mediadora, acompañando, en caso positivo, el acta de reparación con los acuerdos a los que hayan llegado las partes.

2. El documento que incorpore el acta de reparación, se firmará por las partes y por sus representantes legales, si los hubiere, entregándose una copia a cada una de ellas.

3. En este supuesto, el fiscal, valorando los acuerdos a los que hayan llegado las partes, las circunstancias concurrentes y el estado del procedimiento, podrá:

a) Decretar el archivo por oportunidad de conformidad con lo establecido en los artículos I49 y I50, imponiendo como reglas de conducta los acuerdos alcanzados por las partes.

En estos casos, no serán de aplicación los requisitos establecidos en las letras a) y b) del artículo I49.I de esta ley.

b) Proceder por las reglas especiales del procedimiento de conformidad.

En estos supuestos, las víctimas serán siempre oídas aún cuando no se hubieran personado y la sentencia de conformidad incluirá los términos del acta de reparación.

\section{Artículo 160. Mediación en el juicio oral}

Sin perjuicio de lo establecido en los artículos anteriores, el tribunal de enjuiciamiento podrá someter el proceso a mediación cuando todas las partes lo soliciten.

En este supuesto, la mediación se desarrollará de conformidad con lo establecido en el artículo I58.

Si se alcanzare acuerdo, las conclusiones definitivas y la sentencia incluirán la atenuante de reparación.

\section{Artículo 161. Interrupción}

El sometimiento a la mediación durante la tramitación de los juicios de faltas interrumpirá el plazo de prescripción de la correspondiente infracción penal. 